\title{
Impact of overhead line parameters on the short-term voltage stability and its mitigation devices
}

\author{
J.C. del-Pino-López, M. Tostado-Véliz and P. Cruz-Romero \\ Escuela Técnica Superior de Ingeniería, University of Seville \\ Camino de los Descubrimientos s/n, 41092 Sevilla (Spain) \\ Phone/Fax number: +0034 954552847, e-mail: vaisat@us.es
}

\begin{abstract}
This work tackles in a practical way the problem of short-term voltage stability at bulk power systems from the point of view of the overhead lines parameters: length and compactness. With that aim the 9-bus IEEE test system, properly modified to tailor the needs of the study, is simulated in Simulink under high load conditions for different line parameters, analysing the effects of these parameters on the severity of the instability and the recovery rate of the system under different scenarios: no FACTS, SVC and STATCOM. The main findings of the study are included in the conclusions.
\end{abstract}

\section{Key words}

Short-term voltage stability, dynamic load, FACTS, SVC, STATCOM.

\section{Introduction}

The short-term voltage stability (STVS), formerly known as transient voltage stability [1], is a type of voltage stability problem originated from a large (e.g. shortcircuit) or small (e.g. incremental changes of load) disturbance that involves a time frame small enough to not consider slower acting equipment (e.g. tap-changing transformers) but faster components (reaction in seconds) like rapid-response exciters of generators, dynamic loads (e.g. induction motors, electronically controlled loads), FACTS and HVDC [2]. The driving force behind the lack of STVS is the tendency of dynamic loads to restore absorbed power after a disturbance has taken place. Moreover, if there is a loss of a line, the rest of lines that feed the load must face an increase of power and voltage drop. In case of grid survival during the short period after the disturbance, the system is driven by a slower dynamics where the on-load tap changer of transformers, shunt capacitors and over excitation limiter of generators have enough time to react (long-term voltage stability, LTVS).

The voltage stability problem has been analysing since several decades ago $[1,3]$ due to an abnormal number of voltage instability incidents whose ultimate cause was the increasing stress of the grid, approaching to its secure operation limits as a consequence of the load increase and the reduction in the construction of new infrastructure. Due to the identification of most of these instabilities as related with LTVS and the difficulty in modelling the dynamic load, customarily the long-term dynamics has been more deeply analysed and tested $[4,5]$.

On the other hand, throughout the last few years, more and more converter-based renewable energy resources (such as wind and solar power) and HVDC links are being connected to the grid, giving rise to faster dynamics that, together with the high rate of motor loads (including air conditioning) in certain nodes, is raising the concern of scientific community [6-9]. This fact can be aggravated if in the future new massive renewable generation is located far from load centres and new overlay transmission networks or supergrids are built to distribute this energy throughout a continental area. Even though in some regions the HVDC option is now preferred [10], in others could be more convenient the HVAC traditional solution $[11,12]$.

In this paper we study the STVS behaviour of a highly loaded $800 \mathrm{kV}$ 9-bus supergrid after the tripping of a line for two different overhead line designs: conventional and compact. The effect of each configuration is analysed for different line lengths with the same state of load and similar voltage profile.

\section{Model description}

In this paper we have considered the well know IEEE 3machine, 9-bus system [13] shown in figure 1. Simulations have been developed through a Matlab Simulink model as shown in figure 2, although some modifications have been implemented to obtain an $800 \mathrm{kV}$ dynamic model. In this sense, the system consists of three synchronous machines, 9 buses, 6 transmission lines (same length and parameters are always considered), three transformers, three constant impedance loads and one equivalent asynchronous motor load. All three generators are equal, except their rated power, and are representing aggregate hydraulic power plants (Table I). The excitation model corresponds to the Type DC1A excitation system 
the IEEE Standard 421.5 [14]. Also, the multi-band PSS model employed in the simulations is included in this standard with the data shown in Table II. In the same way, the hydraulic turbine and governor models are developed following [15] with all the data shown in Table III.

Data of all transformers are included in Table IV. Finally, all loads are of constant impedance except for the equivalent motor load, which represents five 500 MVA asynchronous machines modelled by a fourth-order model [16] with the parameters shown in Table V.

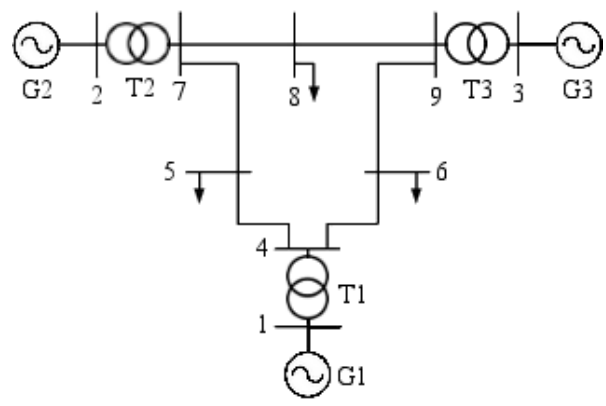

Fig. 1. IEEE 9-bus system.

Table I. - Generator (salient poles) and exciter data

\begin{tabular}{|c|c|c|c|}
\hline Generator & G1 & $\mathrm{G} 2$ & G3 \\
\hline MVA & 5000 & 3700 & 2500 \\
\hline $\mathrm{kV}$ & 13.8 & 13.8 & 13.8 \\
\hline$H(\mathrm{~s})$ & 3.7 & 3.7 & 3.7 \\
\hline$r_{a}(\mathrm{pu})$ & \multicolumn{3}{|c|}{$2.854 \cdot 10^{-3}$} \\
\hline$x_{d}(\mathrm{pu})$ & \multicolumn{3}{|c|}{1.305} \\
\hline$x_{q}(\mathrm{pu})$ & \multicolumn{3}{|c|}{0.474} \\
\hline$x_{d}^{\prime}(\mathrm{pu})$ & \multicolumn{3}{|c|}{0.296} \\
\hline$x_{d}^{\prime \prime}(\mathrm{pu})$ & \multicolumn{3}{|c|}{0.252} \\
\hline$x_{q}^{\prime \prime}(\mathrm{pu})$ & \multicolumn{3}{|c|}{0.243} \\
\hline$x_{l}(\mathrm{pu})$ & \multicolumn{3}{|c|}{0.18} \\
\hline$T_{d}^{\prime}(\mathrm{s})$ & \multicolumn{3}{|c|}{1.01} \\
\hline$T_{d}^{\prime \prime}(\mathrm{s})$ & \multicolumn{3}{|c|}{0.053} \\
\hline$T{ }_{q 0}^{\prime}(\mathrm{s})$ & \multicolumn{3}{|c|}{0.1} \\
\hline \multicolumn{4}{|c|}{ Exciter data (Type DC1A) } \\
\hline $\bar{T} T_{r}(\mathrm{~s})$ & \multicolumn{3}{|c|}{$20 \cdot 10^{-3}$} \\
\hline$K_{a}$ (p.u.) & \multicolumn{3}{|c|}{200} \\
\hline$T_{a}(\mathrm{~s})$ & \multicolumn{3}{|c|}{0.001} \\
\hline$V_{R \max }(\mathrm{pu})$ & \multicolumn{3}{|c|}{7} \\
\hline$V_{R \min }(\mathrm{pu})$ & \multicolumn{3}{|c|}{-7} \\
\hline$K_{e}(\mathrm{pu})$ & \multicolumn{3}{|c|}{1} \\
\hline$T_{e}(\mathrm{~s})$ & \multicolumn{3}{|c|}{0} \\
\hline$K_{f}(\mathrm{pu})$ & \multicolumn{3}{|c|}{0.001} \\
\hline$T_{f}(\mathrm{~s})$ & \multicolumn{3}{|c|}{0.1} \\
\hline
\end{tabular}

Table II. - Multi-band PSS data

\begin{tabular}{|c|c|}
\hline Global gain & 1 \\
\hline$F_{L}(\mathrm{~Hz})$ & 0.025 \\
\hline$K_{L}$ & 5 \\
\hline$F_{I}(\mathrm{~Hz})$ & 0.8 \\
\hline$K_{I}$ & 25 \\
\hline$F_{H}(\mathrm{~Hz})$ & 12 \\
\hline$K_{H}$ & 145 \\
\hline$V_{\text {Lmax }}$ & 0.075 \\
\hline$V_{\text {Imax }}$ & 0.15 \\
\hline$V_{\text {Hmax }}$ & 0.15 \\
\hline$V_{\text {Smax }}$ & 0.15 \\
\hline
\end{tabular}

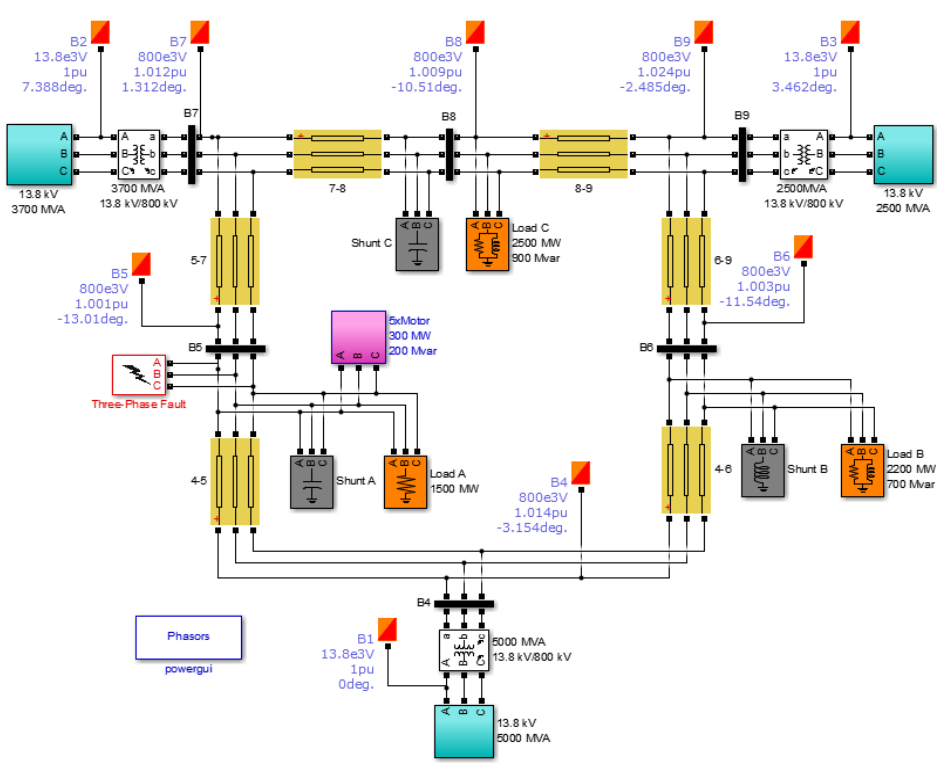

Fig. 2. IEEE 9-bus Simulink model.

Table III. - Hydraulic turbine and governor data

\begin{tabular}{|c|c|}
\hline$K_{a}(\mathrm{pu})$ & $10 / 3$ \\
\hline$T_{a}(\mathrm{~s})$ & 0.07 \\
\hline$g_{\min }(\mathrm{pu})$ & 0.01 \\
\hline$g_{\max }(\mathrm{pu})$ & 0.97518 \\
\hline$v_{g \min }(\mathrm{pu} / \mathrm{s})$ & -0.1 \\
\hline$v_{g \max }(\mathrm{pu} / \mathrm{s})$ & 0.1 \\
\hline$R_{p}$ & 0.05 \\
\hline$K_{p}$ & 1.163 \\
\hline$K_{i}$ & 0.105 \\
\hline$K_{d}$ & 0 \\
\hline$T_{d}(\mathrm{~s})$ & 0.01 \\
\hline$\beta$ & 0 \\
\hline$T_{w}(\mathrm{~s})$ & 2.67 \\
\hline
\end{tabular}

Table IV. - Transformer data

\begin{tabular}{|c|c|c|c|}
\hline Transformer & T1 & T2 & T3 \\
\hline MVA & 5000 & 3700 & 2500 \\
\hline $\mathrm{kV}$ & \multicolumn{3}{|c|}{$13.8 / 800$} \\
\hline$r(\mathrm{pu})$ & \multicolumn{3}{|c|}{0.002} \\
\hline$x(\mathrm{pu})$ & \multicolumn{3}{|c|}{0.12} \\
\hline
\end{tabular}

Table V. - Motor dynamic model parameters

\begin{tabular}{|c|c|}
\hline Rated power $(\mathrm{MVA})$ & $5 \times 500$ \\
\hline Rated votage $(\mathrm{kV})$ & 800 \\
\hline$R_{s}(\mathrm{pu})$ & 0.031 \\
\hline$L_{s}(\mathrm{pu})$ & 0.1 \\
\hline$R^{\prime}{ }_{r}(\mathrm{pu})$ & 0.018 \\
\hline$L^{\prime}{ }_{r}(\mathrm{pu})$ & 0.18 \\
\hline$L_{m}(\mathrm{pu})$ & 3.2 \\
\hline$H(\mathrm{~s})$ & 0.7 \\
\hline
\end{tabular}

On the other hand, two configurations are considered for the $800 \mathrm{kV}$ transmission lines: conventional and compact. The geometry in both cases is shown in figure 3 (conventional configuration) [17] and Fig. 4 (compact configuration derived from the compactness ratio of a 500 $\mathrm{kV}$ compact line [18]). 


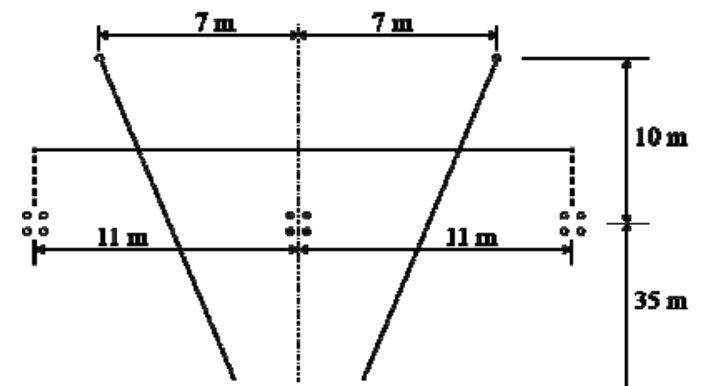

Fig. 3. Arrangement and dimensions of the conventional $800 \mathrm{kV}$ overhead line.

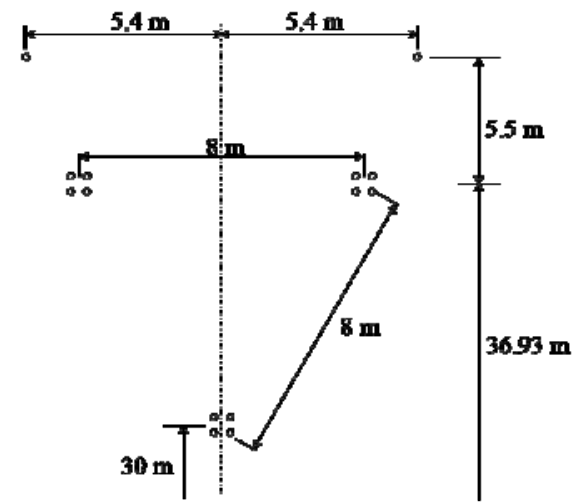

Fig. 4. Arrangement and dimensions of the compact $800 \mathrm{kV}$ overhead line.

The conductor and ground wire employed are those shown in Table V, where four conductors per phase are considered, with a bundle spacing of $0.4572 \mathrm{~m}$. These data lead to the line parameters shown in Table VI for both the conventional and compact configuration.

Table V. - Conductor and ground wire of the $800 \mathrm{kV}$ lines

\begin{tabular}{|c|c|c|}
\hline Type & $\begin{array}{c}\text { Diameter } \\
(\mathrm{mm})\end{array}$ & $\begin{array}{c}\text { D.C. resistance } \\
\text { at } 20^{\circ} \mathrm{C}(\Omega / \mathrm{km})\end{array}$ \\
\hline $\begin{array}{c}\text { ACSR Bersimis } \\
42 / 4.57 \mathrm{~mm} \mathrm{A1.} \\
+7 / 2.54 \mathrm{~mm} \mathrm{St.}\end{array}$ & 35.04 & 0.04242 \\
\hline $\begin{array}{c}7 / 3.66 \mathrm{~mm} \mathrm{St.} \\
\text { ground wire }\end{array}$ & 10.98 & 2.5 \\
\hline
\end{tabular}

Table VI. - Line parameters at $50 \mathrm{~Hz}$

\begin{tabular}{|c|c|c|c|}
\hline Configuration & $r(\Omega / \mathrm{km})$ & $x(\Omega / \mathrm{km})$ & $b_{c}(\mu \mathrm{S} / \mathrm{km})$ \\
\hline Conventional & 0.01162 & 0.26342 & 4.3234 \\
\hline Compact & 0.01162 & 0.22875 & 4.9505 \\
\hline
\end{tabular}

Table VII. - Voltage, phase, P and Q at every bus for the base case (conventional line with a length of $350 \mathrm{~km}$ ).

\begin{tabular}{|c|c|c|c|c|c|}
\hline Bus & Type & $\begin{array}{c}\mathrm{P} \\
(\mathrm{MW})\end{array}$ & $\begin{array}{c}\mathrm{Q} \\
\text { (Mvar) }\end{array}$ & $\begin{array}{c}\mathrm{V} \\
(\mathrm{pu})\end{array}$ & $\begin{array}{l}\text { Phase } \\
\left({ }^{\circ}\right)\end{array}$ \\
\hline 1 & Swing & 2315 & -597 & 1 & 0 \\
\hline 2 & PV & 3300 & -298 & 1 & 7.39 \\
\hline 3 & PV & 2200 & -449 & 1 & 3.46 \\
\hline 4 & \multicolumn{3}{|c|}{-} & 1.014 & -3.15 \\
\hline \multirow{3}{*}{5} & PQ & 1500 & - & \multirow{3}{*}{1.001} & \multirow{3}{*}{-13.01} \\
\hline & Motor & 1500 & 1000 & & \\
\hline & Shunt & - & -300 & & \\
\hline \multirow{2}{*}{6} & PQ & 2200 & 700 & \multirow{2}{*}{1.003} & \multirow{2}{*}{1.31} \\
\hline & Shunt & - & 250 & & \\
\hline 7 & \multicolumn{3}{|c|}{-} & 1.012 & 1.31 \\
\hline \multirow{2}{*}{8} & PQ & 2500 & 900 & \multirow{2}{*}{1.009} & \multirow{2}{*}{-10.51} \\
\hline & Shunt & - & 100 & & \\
\hline 9 & \multicolumn{3}{|c|}{-} & 1.024 & -2.49 \\
\hline
\end{tabular}

With all these data, the influence of the configuration and length of the lines is discussed in the following sections. To that aim, a base case is defined considering all lines of $350 \mathrm{~km}$ with conventional configuration. This results in the initial conditions shown in Table VII for the power delivered and demanded by all generators and loads. Additionally, some shunt devices are implemented (figure 2 ) in order to keep the voltage profile as closer to flat profile as possible, and whose reactive power is recalculated for each line length (for the case of $350 \mathrm{~km}$ the values are shown in table VII).

Starting from the base case at each length and configuration, two fault conditions are analysed at bus 5 (STVS weakest bus due to the presence of the massive motor load):

1) Type I: Three-phase transient fault at bus 5 during a certain number of cycles without considering any line trip.

2) Type II: Three-phase fault at bus 5 during a certain number of cycles followed by a line trip (either 4-5 or 5-7 lines).

Moreover, in the following sections, it will be also discussed the performance of the line configuration joined with the presence of typical FACTS employed to improve the STVS of power systems, like SVC or STATCOM. In this sense, the standard phasor models included in the Matlab-Simulink library are employed in the simulations, with the parameters shown in tables VIII and IX.

Table VIII. - STATCOM data

\begin{tabular}{|c|c|}
\hline Rated power (MVA) & 200 \\
\hline Rated votage $(\mathrm{kV})$ & 800 \\
\hline Converter impedance (pu) & $\begin{array}{c}R=0.0073 \\
L=0.22\end{array}$ \\
\hline DC link voltage $(\mathrm{kV})$ & 40 \\
\hline DC link total capacitance $(\mathrm{F})$ & $3.75 \cdot 10^{-4}$ \\
\hline \multicolumn{2}{|l|}{ Voltage control } \\
\hline Reference voltage (pu) & 1 \\
\hline $\begin{array}{c}\text { Rate of change of reference } \\
\text { voltage }(\mathrm{pu} / \mathrm{s})\end{array}$ & 10 \\
\hline Droop (pu) & 0.03 \\
\hline $\mathrm{V}_{\mathrm{AC}}$ regulator gains & $\begin{array}{c}K_{p}=5 \\
K_{i}=1000\end{array}$ \\
\hline $\mathrm{V}_{\mathrm{DC}}$ regulator gains & $\begin{array}{l}K_{p}=0.1 \cdot 10^{-3} \\
K_{i}=20 \cdot 10^{-3}\end{array}$ \\
\hline Current regulator gains & $\begin{array}{c}K_{p}=0.3 \\
K_{i}=10 \\
K_{f}=0.22\end{array}$ \\
\hline
\end{tabular}

Table IX. - SVC data
\begin{tabular}{|c|c|}
\hline Rated power (MVA) & 200 \\
\hline Rated votage (kV) & 800 \\
\hline Reactive power limits (MVA) & $\begin{array}{c}-200 \\
+200\end{array}$ \\
\hline \hline \multicolumn{2}{|c|}{ Voltage control } \\
\hline \hline Reference voltage (p.u.) & 1 \\
\hline Droop (p.u.) & 0.03 \\
\hline Voltage regulator gains & $K_{p}=0$ \\
& $K_{i}=300$ \\
\hline
\end{tabular}




\section{Results for conventional configuration}

Considering all lines with conventional configuration, the voltage profile at bus 5 is shown in Fig. 5 as a function of the length of all transmission lines after a Type I fault. As can be observed, for a 12 cycles fault, the voltage at bus 5 is only recovered for lines of $350 \mathrm{~km}$ and $400 \mathrm{~km}$, but for larger ones the voltage collapses.

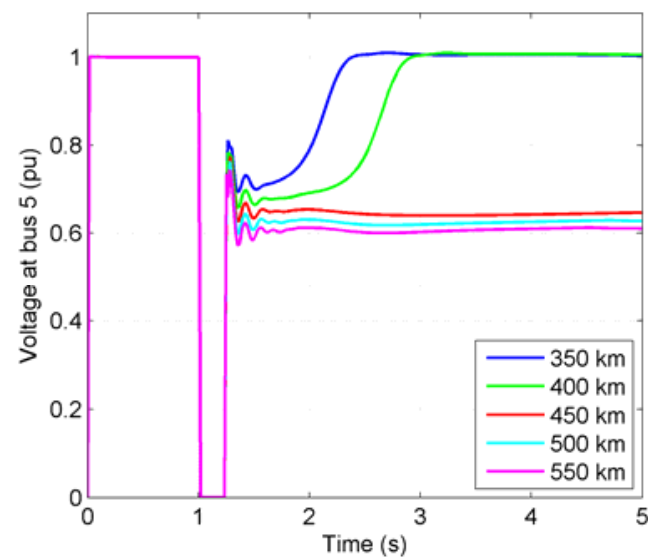

Fig. 5. Voltage at bus 5 for a three-phase fault (12 cycles).

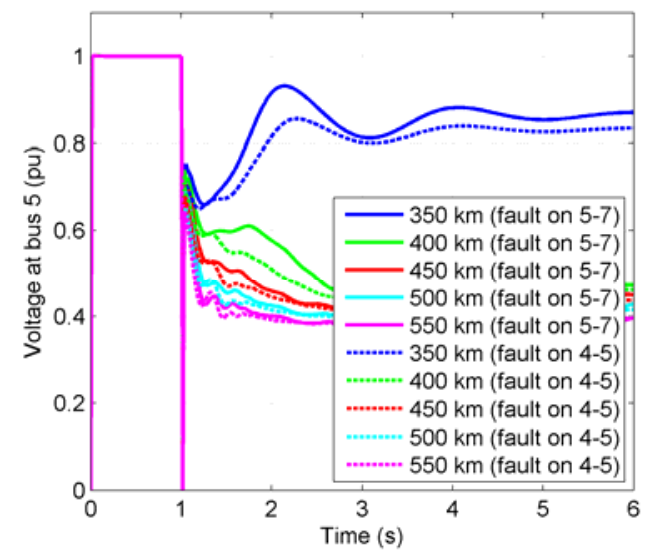

Fig. 6. Voltage at bus 5 during outage of the lines 4-5 or 5-7.

In the case of a Type II fault, figure 6 shows the behaviour of the voltage when either the line 4-5 or line 5-7 trip after 1 -cycle three-phase short circuit. It is easily observed that only for lines of $350 \mathrm{~km}$ the voltage is barely recovered after the line outage.

On the other hand, regarding the Type II fault, figure 6 also shows that the evolution of the voltage at bus 5 is worse after the outage of line 4-5 rather than after the outage of line 5-7. For these reasons, in the following sections only the outage of line 4-5 is considered for this type of fault.

Therefore, from these analyses it is easily concluded that for long line lengths some counter-measures are required for improving the response of the voltage at this bus.

\section{Results for compact configuration}

As mentioned earlier, bus 5 is the weakest one because of the dynamic response of the equivalent motor load during fault conditions. To overcome this problem, the use of a compact configuration for one of the transmission lines linked to bus 5 is now analysed. This implies to change the values of the shunt devices at load buses in order to obtain again the voltage levels observed in the base case (column V of Table VII). For this new situation, the influence of the length of all transmission lines is analysed as follows.

\section{A. Impact on the voltage at most critical bus}

In the case of a Type I fault (12 cycles), figure 7 shows the evolution of the voltage at bus 5 as a function of the line length. Comparing the results from Fig. 5 and Fig. 7a, two main conclusions are derived:

1) The use of a compact configuration, either in line 4-5 or line 5-7, leads to a faster response of the voltage (cases of $350 \mathrm{~km}$ and $400 \mathrm{~km}$ ).

2) Compact lines also improve the voltage response at larger lengths (the voltage is now recovered for 450 km line).

These conclusions are also observed in figure $7 \mathrm{~b}$, where it is compared the results for conventional and compact configurations (lines 4-5 and 5-7). In this particular case, it is easily observed the noticeable improvements introduced by the compact configuration in comparison with the conventional one.

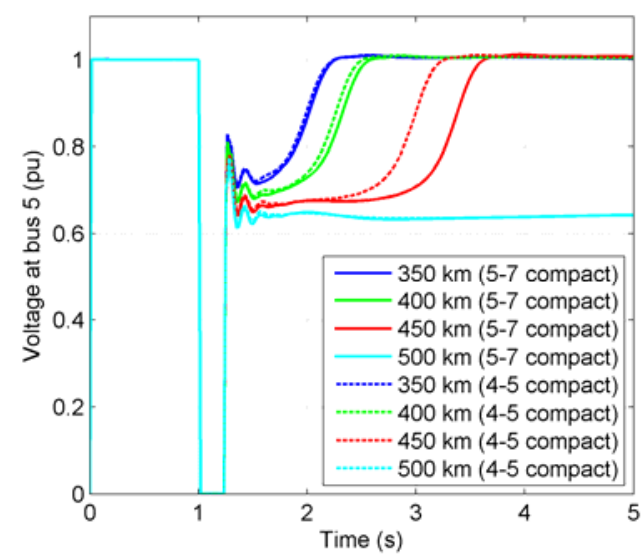

(a)

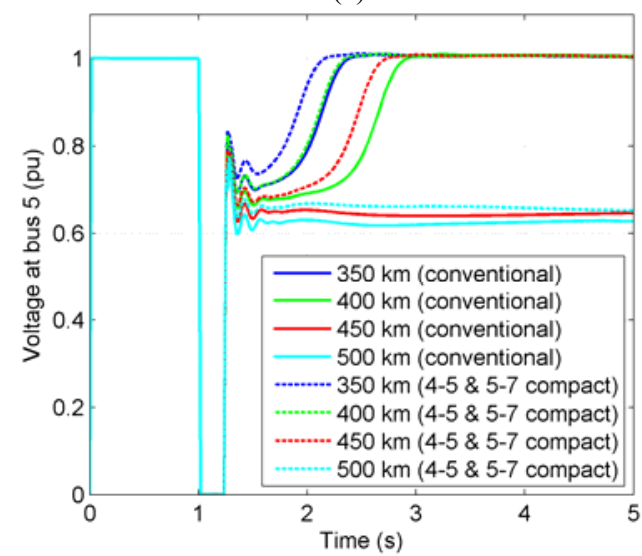

(b)

Fig. 7. Voltage at bus 5 for a three-phase fault (12 cycles) with (a) compact configuration in the lines 4-5 or 5-7 and (b) compact configuration in both lines. 
Regarding a Type II fault, only the outage of line 4-5 is now considered (worst case), so the line 5-7 is replaced by a compact configuration. In this situation, Fig. 8 shows the results obtained for conventional and compact configurations for a trip of the line 4-5 after a 1 cycle three-phase fault. As can be observed, when all the lines are in conventional configuration, the voltage is only recovered for the shortest lines case $(350 \mathrm{~km})$. Conversely, if just line 5-7 is in compact configuration, not only the voltage is recovered faster and achieves a greater value, but also voltage is recovered when all lines are larger $(400 \mathrm{~km})$.

As a consequence, from these results it can be concluded that just rearranging some lines in compact configuration, the STVS at the most critical bus of the system improves noticeably. In any case, now it is analysed the use of this configuration joined with the presence of some FACTS devices commonly employed to improve the SVTS of power systems, like STATCOMs or SVCs.

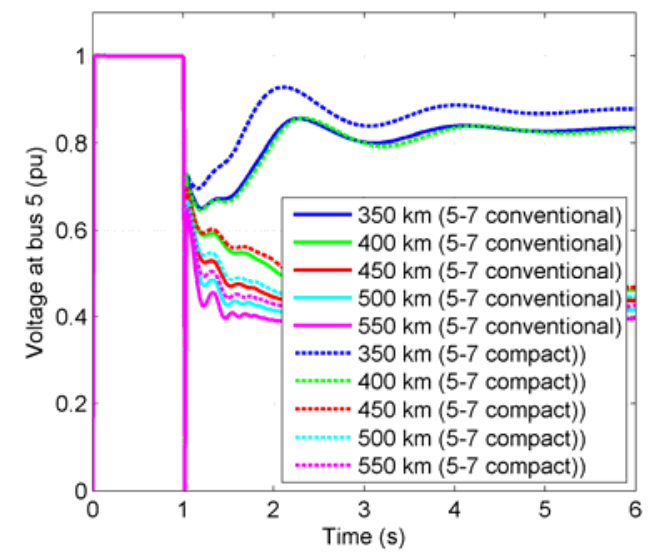

Fig. 8. Voltage at bus 5 during outage of the line 4-5 (1 cycle fault) for conventional and compact configurations in the line 5 7.

\section{B. Impact on the SVC and STATCOM effectiveness}

If we now consider the presence of a SVC or STATCOM installed at bus 5 , the response of the voltage at this bus should be improved either for Type I or Type II faults. If also line 5-7 is in compact configuration, the stability may also be improved. The results obtained in this situation for a Type I fault (12 cycles) are shown in Fig. 9, where it is represented the evolution of the voltage at bus 5 when installing a 200 Mvar SVC (Fig. 9a) or a 200 Mvar STATCOM (Fig. 9b) at bus 5 .

As can be observed, when any of the FACTS is installed, the results for the conventional and compact configurations are very similar for the shorter line lengths, although the voltage response is relatively faster for the compact arrangement. However, the difference between both line configurations starts to be remarkable when the length of all lines is increased. In particular, this situation is observed for lines of $450 \mathrm{~km}$ (either for the SVC or the STATCOM case), where the use of a compact configuration in the line 5-7 improves noticeably the voltage recovery at bus 5 .

On the other hand, for the type II fault, the voltage at bus 5 evolves as shown in figure 10, where a SVC (10a) or a STATCOM (10b) are installed in that bus.

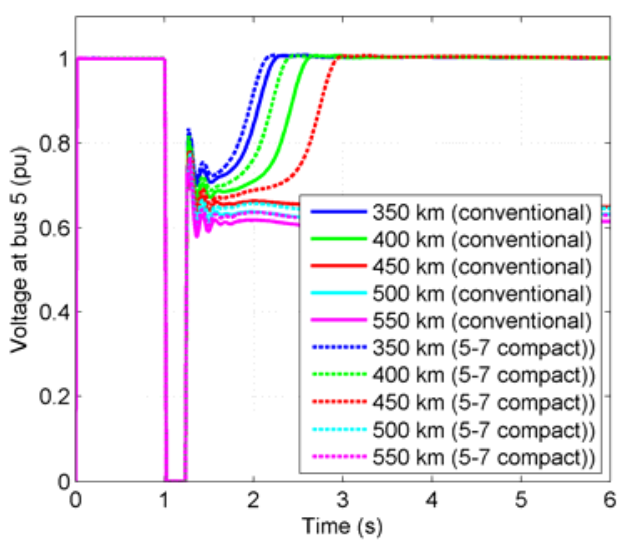

(a)

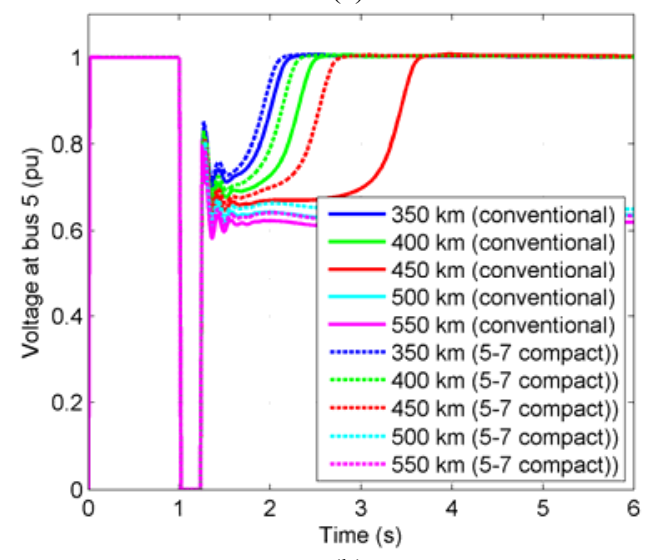

(b)

Fig. 9. Voltage at bus 5 during a three-phase fault in the line 5-7 when installing a 200 Mvar (a) SVC or (b) STATCOM.

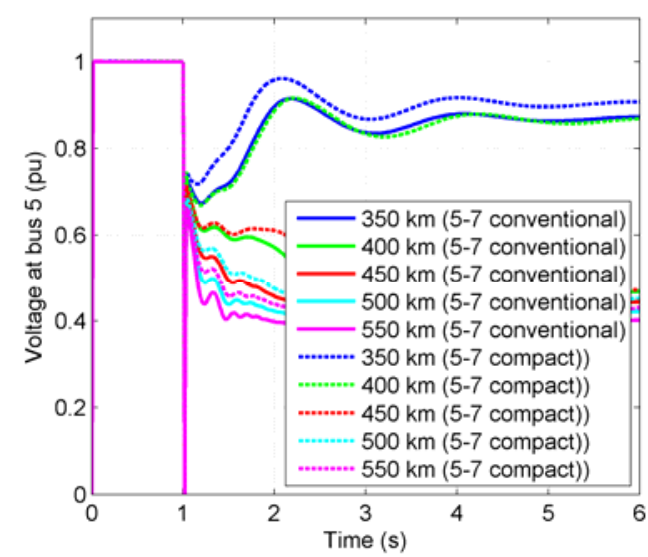

(a)

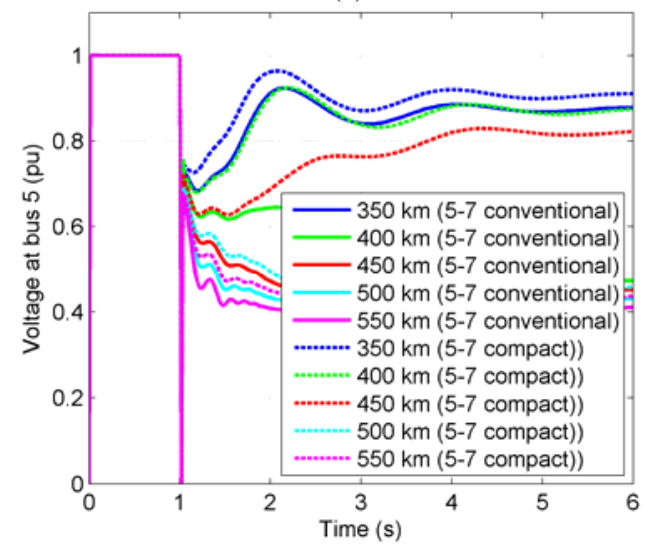

(b)

Fig. 10. Voltage at bus 5 during an outage of the line 4-5 when installing a 200 Mvar (a) SVC or (b) STATCOM. 
As can be observed, while for conventional lines the voltage collapses for line lengths greater than $350 \mathrm{~km}$, for compact lines this happens for lines greater than $400 \mathrm{~km}$ when the SVC is installed, or greater than $450 \mathrm{~km}$ if we consider the use of a STATCOM.

\section{Conclusions}

The compactness of overhead lines modifies the series and shunt reactance of the line, bringing advantages to several aspects, like less environmental impact and improved operation both at steady state and transient operations. In this paper we explore the beneficial effects of compacting an HVAC $800 \mathrm{kV}$ line on the short term voltage stability, concluding that the compactness of the lines closer to the load buses with a great proportion of motors improves the short term voltage stability after a short-circuit at that bus, being more apparent this fact for longer lines, where the stability can be jeopardized in case of fault. Moreover, the compactness makes the improvement of fast-acting reactive compensation devices like SVC or STATCOM clearer, especially when longer lines are present. After this research further studies are being opened to extend the analysis to real networks and compare the performance of a compacted line with the series compensation by FACTS.

\section{Acknowledgement}

This work has been supported by the Spanish Ministry of Science \& Innovation under grant ENE2013-48428C2-1-R.

\section{References}

[1] C.W. Taylor, "Power System Voltage Stability", Mc Graw Hill, New York, 1994.

[2] IEEE/CIGRE Joint Task Force on Stability Terms and Definitions, "Definition and Classification of Power System Stability", IEEE Transactions on Power Systems, vol.19, no.2, May 2004.

[3] T.Van Cutsem, C.Vournas, "Voltage Stability of Electric Power Systems", Springer, New York, 2008.

[4] IEEE Power System Dynamic Performance Committee, "Test Systems for Voltage Stability and Security Assessment", Technical Report, PES-TR19, 2015.

[5] C. Vournas, V. Nikolaidis, A. Tassoulis, Experience from the Athens blackout of July 12, 2004, IEEE PowerTech, St. Petersburg, June 2005.

[6] E.Z.Abdel-Aziz et al., "Voltage stability improvement in transmission network embedded with photovoltaic systems", ENERGYCON, Leuven, April, 2016.

[7] K.Kawabe and K.Tanaka, "Analytical method for shortterm voltage stability using the stability boundary in the PV plane", IEEE Trans. on Power Systems, vol.29, no.6, Nov. 2014.

[8] Y.Xu et al., "Assessing short-term voltage stability of electric power systems by a hierarchical intelligent system", vol.27, no.8, Aug. 2016.

[9] Y.Dong et al., "An integrated high side var-voltage control strategy to improve short-term voltage stability of receiving-end power systems", IEEE Trans. on Power Systems, vol.31, no.3, May 2016.

[10] M. Callavik et al., "Roadmap of the first phase of the European Supergrid", Cigré Belgium Conference, March 2014.
[11] AEP, "Interstate Transmission Vision for Wind Integration", March 2007.

[12] V.Krishnan et al, "Nation-wide transmission overlay design and benefits assessment for the U.S.”, Energy Policy, no.56, 2013.

[13] P. M. Anderson and A. A. Fouad, "Power System Control and Stability". New Delhi, India: Wiley, 2002.

[14] "IEEE Recommended Practice for Excitation System Models for Power System Stability Studies", IEEE Std. 421.5, 2006.

[15] IEEE Working Group on Prime Mover and Energy Supply Models for System Dynamic Performance Studies, "Hydraulic Turbine and Turbine Control Models for Dynamic Studies," IEEE Trans. on Power Systems, Vol. 7, No. 1, February, 1992, pp. 167-179.

[16] P. C. Krause, O. Wasynczuk and S. D. Sudhoff, "Analysis of electric machinery and drive systems", IEEE Press, $2^{\text {nd }}$ Edition, 2002.

[17] H. Wei-Gang, "Analysis and design of $765 \mathrm{kV}$ transmission line based on electric and magnetic fields for different line configuration", IEEE Trans. on Power Delivery, vol.18, no.3, July 2003.

[18] K A. Vyas and J. G. Jamnani, "Study on conductor configuration of 500-kV Chang-Fang compact line", IEEE 6th International Conference on Power systems (ICPS), New Delhi, India, 4-6 March 2016. 